\title{
Gênero e consumo no espaço doméstico em perspectiva transnacional*
}

Joana Mello de Carvalho e Silva**

Gênero e consumo no espaço doméstico: representações na mídia durante o século XX na Argentina e no Brasil é o título do livro organizado por Inés Pérez e Marinês Ribeiro dos Santos a partir de artigos apresentados no $10^{\circ}$ Seminário Internacional Fazendo Gênero (2013). A publicação tem como objetivo analisar, por meio dos artefatos, práticas e difusão do consumo, a construção de noções de feminilidades e masculinidades que incidem sobre a divisão sexuada do trabalho, a organização, a concepção e a ocupação do espaço habitado.

Temas afins foram pesquisados pelas organizadoras em suas teses de doutorado a partir dos campos da história da família e do design e da perspectiva de gênero. Enquanto Pérez (2012) analisou as transformações nas estruturas familiares na Argentina dos anos 1940 e 1970 em relação às dinâmicas de gênero e ao processo de industrialização da vida doméstica, Santos (2015) investigou as relações entre as transformações de gênero no Brasil dos anos 1960 e 1970 e a assimilação da linguagem pop no design de produtos. No desenvolvimento das pesquisas foi ficando clara a centralidade do consumo para a compreensão da modernidade, uma vez que a estruturação de um mercado diversificado de artefatos produzidos em massa foi acompanhada por discursos que contribuíram para a estratificação das vendas $e$ a

\footnotetext{
* Recebida em 17 de março de 2019, aceita em 30 de abril de 2019. Resenha de PÉREZ, Inés; SANTOS, Marinês Ribeiro dos (org.). Gênero e consumo no espaço doméstico: representaçóes na mídia durante o século $X X$ na Argentina e no Brasil. Curitiba, Ed. UFPR, 2017.

** Profa. Dra. do Departamento de História da Arquitetura e Estética do Projeto da Faculdade de Arquitetura e Urbanismo, USP, São Paulo, SP, Brasil. joanamello@usp.br / https://orcid.org/0000-0001-5108-8186.
} 
desigualdade de aquisição por gênero, classe e raça, incidindo nos ambientes urbano e doméstico, este último alvo privilegiado da produção industrial no período.

O consumo ao qual as autoras se referem é entendido como um ato que não se limita à compra, mas envolve usos, apropriações e descartes motivados por ideias e desejos que participam da construção de nossas identificações de gênero (Butler, 2001) e modos de vida (Pérez; Santos, 2017:7). Nesse sentido, longe de ser um ato individual e passivo, o consumo envolve dinâmicas sociais e culturais mais amplas, além de mecanismos de classificação e distinção como têm defendido Campbell (1995), Canclini (1999), Daunton e Hilton (2001), Miller (2013) e Cohen (2004).

As autoras argumentam ainda que as atividades que envolvem o consumo na modernidade são motivadas e reforçam dualismos recorrentes como público/privado, urbano/doméstico, homem/ mulher, coletivo/ individual, produção/ consumo, ativo/ passivo. Se essas oposições devem ser compreendidas historicamente enquanto força discursiva, elas são arbitrárias $e$ mais fluidas do que se relata, variando segundo classe, raça/ etnia, geração e gênero (Hollows, 2008; Heynen, 2005; Prost 1992). Lembrando da máxima do feminismo de segunda onda, o esforço das autoras é justamente o de analisar e problematizar essas dicotomias a partir dos artefatos domésticos, suas práticas $e$ consumo numa perspectiva interseccional.

Além das questões gerais aqui apresentadas, outras específicas foram levantadas pelas organizadoras, relativas às particularidades que "caracterizam os usos e apropriações locais de novas tecnologias domésticas e de saberes a elas associados"; ao lugar que "ocupam os discursos dos meios de comunicação na conformação de tais particularidades"; aos "elementos que podem ser percebidos como similares aos observadores em outros casos $e$ contextos"; a como se "configuraram os discursos de 'especialistas' no cenário latino-americano" $e$, finalmente, às "estratégias empregadas para a veiculação na mídia de massa" (Péréz; Santos, 2017:13). 
Foi procurando respondê-las que as organizadoras selecionaram os artigos que compóem o livro $e$ o estruturaram em duas partes. A primeira, intitulada "Trabalho doméstico e consumo: disciplinamento, saberes e representações", traz três artigos apresentados cronologicamente que relacionam o processo de massificação e diversificação das práticas de consumo com o processo de profissionalização das donas de casa, levados a cabo por um conjunto de atores sociais, cujos discursos circulavam por manuais de dona de casa e de economia doméstica, propagandas $e$ revistas. Na segunda parte, intitulada "Gênero, classe $e$ nacionalidade na promoção do consumo de tecnologias domésticas", outros três artigos, igualmente apresentados em ordem cronológica, analisam os discursos de promoção do consumo de eletrodomésticos por meio de documentos diplomáticos, revistas, propagandas e entrevistas. O livro se encerra com um epílogo, o artigo "De empregada a 'empreguete': das lutas simbólicas na telenovela brasileira", que, ao tratar da ascensão da classe $\mathrm{C}$ no Brasil $e$ das transformações que se procederam em suas representações em função de sua assimilação como consumidoras, serve como um contraponto temporal $e$ social às experiências relatadas nos artigos anteriores.

A primeira parte abre com o artigo " $\mathrm{El}$ hogar como quehacer: los saberes de la economia doméstica en el debate sobre la cuestión social (Argentina, 1890-1920)", escrito por Paula Lucía Aguilar. A autora argumenta que a economia doméstica uma disciplina que se institui na Argentina naquele momento como uma política de Estado voltada especialmente para as classes trabalhadoras - tinha um caráter duplo: moral $e$ econômico. Assim, de um lado atendia ao desejo de ordem e domesticação feminina, de outro incentivava as práticas de poupança, ou seja, a economia de recursos entendida como uma medida essencial para a ascensão social da família $e$ a prosperidade da nação. Embora, a questão da autora seja certeira e o texto traga análises precisas, não fica claro por quais caminhos o Estado agia, nem como a sua ação atingia as camadas populares. De todo modo, é interessante notar como, também 
aqui no Brasil, a economia doméstica respondia à preocupação com o equilibrio financeiro das famílias, sobretudo as de classe média, e como isso tinha relação, por outro lado, com o incentivo ao consumo.

O segundo artigo "Saberes femininos: la cocina y la transmisión de las recetas en los clivajes de las lógicas del consumo (Argentina, 1880-1945)" é assinado por Paula Caldo que acompanha a profissionalização do trabalho doméstico por meio das mudanças nas práticas e circulações de receitas culinárias. De registros locais, como marcas de uma memória coletiva e de um conhecimento oral, as receitas teriam se constituído em dispositivos de educação, consumo e disciplinamento que promoviam a aquisição de novos produtos e equipamentos, ao mesmo tempo que conformavam duas das funções femininas consideradas centrais à época: a alimentação e o cuidado da prole, dos futuros cidadãos. A autora enfatiza o lugar que as mulheres ocuparam na sociedade de consumo e na divisão sexuada do trabalho, articulando bem as esferas de produção $e$ consumo, pública e privada, e mostrando como nesse processo houve inversões inesperadas com a profissionalização de algumas mulheres que, para além do espaço doméstico, tornaram-se escritoras, jornalistas, professoras, e alcançaram o espaço da cidade. Havia, naquele momento, como bem observa Rubino (2017), uma simbiose entre as identidades sociais e profissionais do gênero feminino, e, portanto, entre o mundo doméstico e o profissional, entre a submissão e a subversão.

O capítulo que fecha essa primeira parte, "O trabalho doméstico na revista Claudia (1970-1989)", escrito por Soraia Carolina de Mello, dá um salto temporal e regional ao abordar as representações do trabalho doméstico presentes no periódico e da relação dessas representações com as práticas de consumo no Brasil. Embora a autora avance na análise dos trabalhos creditados às donas de casa, distinguindo-os por classe social $e$ revelando a hierarquia que os presidia, ainda há muito o que se investigar em relação àqueles serviços que eram, pelos menos entre as classe médias e altas, executados por empregadas 
domésticas. Nesse sentido, é revelador notar como, no horizonte da Constituição de 1988, quando as empregadas domésticas foram reconhecidas como uma categoria profissional, a revista abriu espaço para um conjunto nostálgico de reportagens que lastimavam o fato de que já não existiam "Marias" como antigamente. Esse lamento foi reeditado nos anos $2000 \mathrm{com}$ a PEC das Empregadas Domésticas, talvez e infelizmente, com ainda maior virulência e consequências.

A segunda parte abre com o capítulo "A promessa do American Way of Life para a América Latina: domesticidade, tecnologia e consumo (1940-1945)" assinado por Sol Glik. A autora mostra os investimentos do governo norte-americano durante e após a Segunda Guerra Mundial no controle do nazifascismo, e depois do comunismo, e na promoção da reestruturação do parque industrial em direção ao mercado doméstico. Articulando elementos políticos com o cotidiano, a vida doméstica $e$ as relações de gênero, Glik afirma que esses investimentos, sintetizados no American Way of Life, foram um instrumento de guerra a um só tempo econômico e cultural. Um instrumento que promovia por meio de vários veículos (ela enfoca o periódico The Reader's Digest, cujos vínculos com o Office Coordinator of Interamerican Affairs são conhecidos) associações recorrentes entre liberdade, democracia, tecnologia, ciência $e$ felicidade, num jogo de espelhos entre o espaço público da política e o espaço privado da família. O interessante em sua análise é ver como a perspectiva transnacional e, portanto, a decisão por abordar as versões norte-americana, argentina $e$ brasileira do referido periódico, contribuiu para revelar a estratégia de largo alcance dos Estados Unidos na construção de uma posição central no âmbito mundial, mas ao mesmo tempo, mostrar a diversidade de sentidos que ela assumiu e também as resistências que sofreu nos diferentes contextos. Além disso, é impressionante ver que muito antes do fim do conflito mundial, os EUA já se preocupavam com a necessária adequação da indústria de guerra a outros campos da produção nacional, reconhecendo no espaço doméstico o seu principal ramo de investimento. A 
expansão das classes médias orienta e dá suporte a esse projeto que, no Brasil, se consolida na passagem dos anos 1950 para os 1960.

No artigo seguinte, "Confort para el Pueblo y liberación para el ama de casa: género, consumo y heladeras en Argentina (1930-1960), Pérez recupera parte de seu doutorado, mostrando as especificidades do processo de tecnificação do lar em Mar del Plata. Para tanto, enfoca um eletrodoméstico em específico, a geladeira, que em muitos lares daquela localidade, especialmente os de famílias com menor poder aquisitivo, foram instaladas na sala de jantar e não na cozinha. Analisando a sua divulgação $e$ práticas de consumo a partir da articulação de escalas diversas do objeto à infraestrutura urbana de abastecimento de energia elétrica; da casa ao mercado de vendas - Péréz dividiu o artigo em duas partes. Na primeira, dedicada à análise das condições de consumo de geladeiras elétricas na cidade, a autora recupera o conjunto de ações do governo peronista na democratização do consumo de eletrodomésticos que envolveram investimentos na indústria local, redes de água, eletricidade e gás. Ao mesmo tempo, investiu-se em publicidade, reafirmando a centralidade feminina na administração do lar, a sua importância no controle dos gastos domésticos e na promoção do consumo. A segunda parte se concentra nos significados atribuídos a esse artefato pelos consumidores, recuperados por meio de entrevistas que apontaram uma hierarquia clara entre os eletrodomésticos. Se liquidificadores, batedeiras e outros equipamentos do gênero eram vistos como "coisas de mulher", servindo apenas para diminuir o seu esforço individual, a geladeira era entendida como item de primeira necessidade que representava para o homem a capacidade de, como provedor, garantir a sobrevivência da família, e para a mulher o seu dom de bem administrar o lar e de garantir o bem-estar de todos. Seria essa representação dupla de sucesso que faria com que a geladeira - um item caro, difícil de ser adquirido por essas famílias - ficasse como um troféu na sala de jantar e não na cozinha. 
O capítulo que encerra a segunda parte, "Representações de feminilidades nos discursos sobre consumo de tecnologias domésticas nas revistas Casa \& Jardim (Brasil, década de 1960)" é assinado por Ana Caroline de Bassi Padilha e Marinês Ribeiro dos Santos. As autoras argumentam que os eletrodomésticos e seus meios de divulgação serviram como pedagogias de gênero que buscaram conciliar imagens e condutas femininas tradicionais com a modernização das práticas de consumo doméstico. $\mathrm{O}$ foco das análises são as peças publicitárias veiculadas nas revistas, merecendo destaque a acuidade $e$ a perspicácia com que são feitas, confirmando a força discursiva que as imagens têm. A partir delas, as autoras afirmam a recorrência de três papéis femininos o de rainha do lar, como a figura que garante a coesão $e$ o bemestar familiar; o de cozinheira, cujo trabalho mesclaria cuidados com a prole e a sedução do marido; e o de dona de casa eficiente preocupada com a economia doméstica - que apontam como, entre as classes médias, o consumo de eletrodomésticos envolveu não apenas transformações de práticas e costumes, como a própria produção de trabalho no interior da habitação. Um trabalho que, no caso das donas de casa, assumiu ares profissionalizantes e científicos, mas que no tocante às empregadas domésticas era silenciado ou naturalizado, o que é uma outra forma de invisibilidade. A sua presença explica, em parte, porque aqui e entre esses grupos sociais, ao contrário do analisado por Pérez, os eletrodomésticos permaneceram confinados na cozinha.

Além das virtudes já destacadas, o livro tem outras duas qualidades que merecem destaque. A primeira tem relação com a perspectiva transnacional, que, embora não seja anunciada pelas organizadoras, afirma-se ao apontar a correlação entre os processos de modernização dos Estados Unidos, Europa e América Latina e como eles incidiram e foram constituídos também a partir do espaço doméstico. Nesse sentido, a expansão das classes médias e o ideal da casa própria tecnificada norteamericana perpassaram o imaginário desses territórios, sempre com acentos e arranjos regionais próprios. Essa diversidade de 
apropriações do American Way of Life não se explica apenas regionalmente, mas em função de experiências específicas de classe, gênero e raça - e essa é a segunda qualidade do trabalho. $\mathrm{Se}$ os dois primeiros marcadores sociais foram mais explorados pelas autoras, há que se avançar em relação à raça e, mais do que isso, na interseção entre esses marcadores sociais para que se aprofundem e complexifiquem ainda mais as análises sobre consumo e espaço doméstico na América Latina.

\section{Referências bibliográficas}

BUTLER, Judith. El género en disputa: el feminism y la subversion de la identidad. Buenos Aires, Paidós, 2001.

CAMPBELl, Colin. The sociology of consumption. In: MiLler, Daniel (ed.). Acknowledging consumption: a review of studies. London, Routledge, 1995, pp.96-126.

CANClinI, Néstor García. Consumidores e cidadãos: conflitos multiculturais da globalização. Rio de Janeiro, Editora da UFRJ, 1999.

COHEN, Lizabeth. A Consumers' Republic: the politics of mass consumption in postwar America. New York, Random, 2004.

DAUTON, Martin; HILTON, Mattew. The politics of consumption: material culture and citizenship in Europe and America. Oxford, Berg, 2001.

HEYNEN, Hilde. Modernity and domesticity: tensions and contradictions. In: HEYNEN, Hilde; BAYDAR, Gülsüm (ed.). Negotiating domesticity: spatial productions of gender in modern architecture. Abingdon, Routledge, 2005, pp.1-29.

Hollows, Joanne. Domestic cultures. New York, McGraw-Hill, 2008.

MILLER, Daniel, Trecos, traços e coisas: estudos antropológicos sobre a cultura material. Rio de Janeiro, Zahar, 2013.

PÉREZ, Inés; SANTOS, Marinês dos (org.). Gênero e consumo no espaço doméstico: representações na mídia durante o século $X X$ na Argentina e no Brasil. Curitiba, Ed. UFPR, 2017. 
PÉREZ, Inés. El hogar tecnificado: famillias, género y vida cotidiana: 19401970. Buenos Aires, Editora Biblos, 2012.

PROST, Antoine. Fronteiras e espaço do privado. In: PROST, Antoine; VinCENT, Gérard (ed.). História da vida privada, 5: da Primeira Guerra a nossos dias. São Paulo, Companhia das Letras, 1992, pp.13-153.

RUBINO, Silvana. Lugar de mulher: arquitetura e design moderno, gênero $e$ domesticidade. Tese (Livre-docência) - IFHC UNICAMP, Campinas, 2017.

SANTOS, Marinês Ribeiro dos. O design pop no Brasil dos anos 1970: domesticidades e relaçôes de gênero na decoração de interiores. Curitiba, Ed. UFPR, 2015. 